\title{
"I am just shy and timid": Student teachers' explanations for their performances of their presentations
}

\author{
Kadriye Aksoy-Pekacar a (D), Arzu Kanat-Mutluoğlu b * (D), İsmail Hakkı \\ Erten ${ }^{\circ}$
}

a Çanakkale Onsekiz Mart University, Faculty of Education B3 Block, Çanakkale, Turkey

b TED University, Ziya Gökalp cad. No: 48 Kolej, Ankara, Turkey

${ }^{b}$ Hacettepe University, Faculty of Education B Block, Ankara, Turkey

\begin{tabular}{l|l|l} 
Received 13 July 2020 & Received in revised form 30 October 2020 & Accepted 2 November 2020
\end{tabular}

\begin{abstract}
APA Citation:
Aksoy-Pekacar, K., Kanat-Mutluoğlu, A., \& Erten, İ. H. (2020). "I am just shy and timid": Student teachers' explanations for their performances of their presentations. Eurasian Journal of Applied Linguistics, 6(3), 459-480.
\end{abstract}

Doi: $10.32601 /$ ejal.834657

\begin{abstract}
As part of the research on motivation, causal attribution studies have an important role in predicting and improving academic performance since controllable and uncontrollable attributions have an effect on learners' future actions. Following this path, the present qualitative study investigates the attributions of students in an English Language Teaching (ELT) program for the performances of their presentations as part of an oral communication skills course. Upon the completion of the course, a total of 83 second year ELT students scored their performances out of 10 and provided explanations for their performances. This data set illustrated their attributions and estimated future achievements. Data analysis consisted of two phases: first, the students were divided into two groups based on the perceived successes of their performances, and secondly, their explanations were examined with content analysis. The initial analysis showed that 20 students scored themselves as less successful and 63 students scored themselves as successful. It revealed that the less successful group attributed their performances mostly to their mood and lack of effort, both of which are categorized in the internal attributions. In contrast, the successful students attributed their performances to effort, mood, and strategy use, all of which fell into the internal category as well. From these results, it can be concluded that the learners had a higher locus of control in that they attributed their performances to mostly internal attributions. In addition, providing immediate teacher feedback and creating a classroom environment for vicarious learning were effective for increasing learners' effort and motivation for their presentations. These findings may imply that teachers focus on providing immediate feedback and create an effective classroom atmosphere that will probably lead to vicarious learning.
\end{abstract}

(C) 2020 EJAL \& the Authors. Published by Eurasian Journal of Applied Linguistics (EJAL). This is an open-access article distributed under the terms and conditions of the Creative Commons Attribution license (CC BY-NC-ND) (http://creativecommons.org/licenses/by-nc-nd/4.0/).

Keywords: attribution theory; speaking; motivation; causal attributions; oral communication skills

\section{Introduction}

\footnotetext{
* Corresponding author. Tel.: +90 3125850415

E-mail address: kanatarzu@gmail.com

http://dx.doi.org/10.32601/ejal.834657
} 
From the perspective of constructivism in learning, learners constantly try to understand their world and attach meanings to their learning situations (Williams \& Burden, 1997). In this process, they tend to construct beliefs and perceptions about themselves. As it has been often asserted, those beliefs are alterable (Weiner, 1992) and can have an impact on human motivation both quantitively and qualitatively (Dörnyei, 2000). Still, they play an important role in learners' motivation, future actions and even achievement. It is possible to understand what makes people act or refrain from acting in certain ways or how they persevere in the process of learning by looking at their beliefs and perceptions of themselves (Williams \& Burden, 1997). Such a link between human beliefs, motivation and future achievement can be set up by understanding learners' causal attributions for achievement.

Considering the effect of motivation shaped attributions on learning process, the current study aims to explore and illustrate the attributions of English major students, who were taking a specialized course on giving speeches and expressing one's ideas in oral communication. Given the impetus of study on attributions, this paper initially introduces the theory of attribution developed by Weiner $(1992,2010)$ to understand learners' motivation. The paper then describes the methodology pursues in the study and then move to the presentation of results. Finally, the findings are discussed in relation to current knowledge and conclusions are drawn based on the findings.

\subsection{Attribution theory}

Attribution theory, which falls within the cognitive paradigm of motivation studies and was originally developed in educational psychology in the 1980s, is concerned with what individuals see as the causes of their perceived successes and failures in life in general (Mercer, Ryan, \& Williams, 2012). According to Weiner (1992, 2010), understanding the reasons to which individuals attribute their past successes and failures can shape their motivational disposition underlying future action (Dörnyei \& Ryan, 2015). The foundation of this theory lies within this idea: people succeed at some things and fail at some others during their lives. As a part of human nature, they will think back about their experiences and seek explanations or reasons for their successes and failures. By doing so, it is believed that individuals might try to control the factors that affect them and thus continue working either with the hope of repeated success or the attempt to avoid failing again (Hsieh, 2012). Hsieh and Schallert (2008), however, warns that this process is closely related to people's beliefs and as a consequence, attributions may not represent the 'true' reasons for succeeding or failing at a task.

In the most comprehensive model of attribution theory, Weiner (1976) categorized three causal dimensions of attributions: locus, stability, and control. According to Hsieh (2012), locus is concerned with whether the individual attributes the cause to internal or external factors. The second causal dimension, stability, is concerned with whether the cause of an event can be changeable across time and events. The final 
dimension, controllability, is related to how much control individuals perceive they have over a cause. To exemplify each dimension, students having an internal locus of control may attribute the cause to ability or effort and those having external locus of control tend to attribute the cause to luck or the teacher. Ability or personality are often considered to be stable since they are believed not to change over time, whereas effort is believed to be unstable because the person will make a decision with regard to each new situation. Finally, ability along with luck or the teacher are classified as uncontrollable because it is believed that individuals cannot have control over these causes. Strategy use or effort can be categorized as controllable as learners can have control over these factors. Hsieh (2012) states that recognition of learners' attributions carries the utmost importance in achievement settings because the attributions can have a decisive influence on their decisions regarding achievement activities. Even though attributions may not seem to be accurate, they will have a power to influence people's expectancy for success, persistence in the event of failure, and beliefs about their abilities. These, in turn, will influence their motivation and achievement (Weiner, 2000).

There is a close relationship between motivation and attributions since attributions can predict and improve academic performance. If, for instance, people attribute their failure in a particular task to their ability, it is highly possible that they will not try the activity ever again. If they, on the other hand, believe that the cause lay in the insufficient effort that they have put into the task, they will give it another try. In terms of language learning, Hsieh (2012) explains that if learners believe their success in learning a language is due to their effort, they will keep on investing effort in similar tasks. Moreover, if the learners attribute their failure to their ability, they might refrain from future tasks to avoid failure. It can be summarized that if learners attribute the causes to controllable, unstable and internal attributions, they will certainly keep investing effort in the task. On the other hand, if they attribute especially their failures to external, uncontrollable and stable factors, they will most probably give up trying in the subsequent tasks. Undesirable attributions such as task difficulty might decrease learners' willingness to learn and can even increase anxiety. Therefore, it is important to help learners develop attributions that facilitate learning and build higher confidence in themselves.

\subsection{Research on attribution theory in a foreign language context}

Hsieh (2012) claims that a foreign language learning context is interesting to study the effects of attribution especially in the countries where undergraduate learners do not have to take compulsory foreign language courses. Before learning a foreign language, learners make some pre-assumptions of whether they will be successful at learning the language. They will also form some beliefs about whether they will be able to speak the language accurately, and these beliefs can be affected by their opinions of how others might judge them or through observing how their peers perform (Hsieh, 2012). As learners must speak the language publicly in foreign 
language contexts, it can be said that language learning is linked with losing face, risking criticism and also embarrassment.

Learners' attributions (Gürsoy \& Çelik Korkmaz, 2015; Paker \& Özkardeş-Döğüş, 2017), the relationship between attributions and L2 achievement (Erten \& Burden, 2014; Hashemi \& Zabihi, 2011; Hsieh \& Kang, 2010; Pishghadam \& Modarresi, 2008; Pishghadam \& Zabihi, 2011; Zabihi \& Pordel, 2011) and individual variables such as age, gender or culture that might affect learners' attributions have been investigated a great deal (Bayraktar-Erten \& Erten, 2014; Erten, 2009, 2015; Genç, 2016; Satıcılar, 2006) in foreign language contexts. However, when the existing literature on attribution studies is considered, Lian (2012) claims that it is really scarce to find studies investigating attributions and specific L2 learning tasks, such as grammar, speaking, reading, writing and listening. There is thus a need to look into learners' attributions in terms of different language tasks because recognition of these will shed light on their potential future L2 achievement and motivation. In this vein, this study seeks to understand learners' explanations for an required task, which is giving a speech on a self-selected topic by addressing a group of people. This task is obviously a speaking activity. Therefore, the nature of speaking in a foreign language learning environment is considered in line with studies on the issue.

\subsection{The nature of foreign language speaking}

The development of communicative language teaching in the 1970s led the focus of language learning to shift from learning the usage to learning the use of the target language (Larsen-Freeman, 2000). As a consequence, policy makers stated the main objective of English Language Teaching (ELT) in Turkey to be developing learners' communicative skills (Talim Terbiye Kurulu [Board of Education and Discipline], 2006). In spite of this emphasis, British Council and TEPAV (2014) reports that ELT was still observed to remain highly structural in classrooms (Alagözlü, 2012; Işılk, 2011; Uztosun, 2013a) and Turkish learners seem to have difficulty in improving their communication skills in English (EF English Proficiency Index, 2019).

Learners who enroll in ELT departments also lack sufficient development of their communicative skills due to an overdependence on teaching structures in secondary and high schools (British Council \& TEPAV, 2015). According to the curriculum set by the Council of Higher Education in Turkey (YOK), ELT learners are given skill-based intensive courses that focus on developing learners' reading, writing, speaking and listening skills in English. Courses such as oral communication skills taught in two semesters are particularly taught to improve learners' communicative skills as they will become English language teachers upon their graduation. As Uztosun (2013b) states these skill-based courses guide learners to develop their communicative skills in English.

Uztosun (2013b) emphasizes the complex nature of the speaking skill and that it is rather complicated to deal with it as a means of communication. He suggests that language learners should be aware of this complexity and take part actively in the 
classes for practice so as to develop an awareness of distinct features of speaking skills. In addition, he adds that the individual characteristics of learners should be taken into account if there is a desire to engage learners in classroom activities. Individual characteristics such as motivation, self-esteem, willingness to communicate and anxiety are given as the relevant variables regarding the nature of speaking skills. It is a common experience that motivation is an influential factor that might have an impact on learners' performance. Dörnyei (2005) states that it is not possible to attain long-term goals even for people with the most remarkable abilities if they lack sufficient motivation. Moreover, no achievement can be guaranteed even if well-designed curricula and good teaching are offered. Therefore, it is important for teachers to find out learners' motivational states to facilitate learning. An attributionoriented motivation study seems to offer a deeper look into learners' motivations related to L2 specific tasks.

\subsection{Studies on attribution theory and foreign language speaking}

As Lian (2012) mentioned it is very uncommon to find studies focusing on learners' attributions on specific L2 tasks such as speaking. There are as yet only a few studies that investigate learners' attributions for their successes and failures in completing L2 tasks. Lian (2012), for instance, investigated learners' attributions for their failures and successes in completing L2 listening tasks and the reasons for their attributions. In another study, Yllmaz (2012) investigated university students' attributions for the successes and failures in second language reading. Faber (2019) conducted a study aiming at understanding preadolescent English as a foreign language (EFL) learners' attributions for grammar success and failure. SorianoFerrer and Alonso-Blanco (2020) determined the frequency of successful and unsuccessful activities of each language skill such as reading, writing, speaking and listening per English level (e.g. A1, A2, B1 and B2) and compared learners' causal attributions on successful and failure authentic tasks in an EFL context. Finally, Demir (2017) and Mali (2015) focused on speaking tasks and investigated learners' attributions for speaking English.

Mali (2015) carried out research with eighteen students in an Indonesian context to understand learners' attributions for their English-speaking development. The students had a language proficiency of intermediate up to advanced level and joined an English-speaking program which was part of a compulsory extracurricular program aiming to improve learners' speaking skills. By using an open-ended questionnaire and interview, the researcher tried to unveil learners' attributions for their speaking development by adopting a grounded theory approach (Strauss \& Corbin, 1990). The results clearly indicated that in this context, learners attributed their English-speaking development to a clear purpose of doing particular English speaking activities, the strategy to develop speaking skills, and the positive relationships between the students and the teacher as well as among the students themselves as the primary attributions. 
Another study by Demir (2017) also aimed at finding learners' attributions for success and failure in speaking English. The participants were chosen from a language school of a state university in Turkey and there were 104 students in total. To understand learners' attributions, the researcher used an adapted version (Koçyiğit, 2011) of the Causal Dimension Scale (McAuley, Duncan, \& Russell, 1992) and the data were subject to descriptive statistics. The results indicated that in this particular context, students tended to attribute their successes in speaking English to more personal controllable and internal reasons such as practice/exposure, determination/interest, but their failures to more unstable and externally controllable factors such as lack of study/practice, ineffectiveness of the learning environment and lack of self-confidence/anxiety. The author further investigated the impact of gender and students' undergraduate programs in which they would later study at the university. There was only one difference observed in the attributions of their failures in speaking between the students of ELT departments and Civil aviation management.

Finally, the learners of lower level of English (e.g., A1 and A2) regarded speaking activities as the least successful ones although the frequency was not very different among B1 and B2 level learners (Soriano-Ferrer \& Alonso-Blanco, 2020). Among the speaking activities in the same study, learners from all language levels regarded giving a presentation and/or speech as an unsuccessful activity.

\subsection{Rationale for this study}

Good speaking skills are a key to become a good public speaker. As language teachers, it is our job to be good public speakers because each time we step forward to say something in the classroom, we make a speech. Tomic (1997, cited in Petek, 2014) mentions that it is the teacher's role to encourage and direct communicative acts. He further states for professional and complete communication, the teacher has to have control over it and recognize its effect on the listeners and how it is being received.

Lightfoot (n.d.) says that many students can get incredibly nervous the first time they have to do a speech in front of their classmates and teachers. When they graduate, they will need to stand up and speak in front of their learners. Teaching students the necessary skills for doing this will therefore help them to do this more successfully. This can in turn lead to an increase in learners' confidence and achievement as well. As Lightfoot suggests, students' overall fluency can be developed by public speaking as they will consider how they speak as well as what they say. This is good for improvement in speaking either in public or in other situations.

The relevant literature (e.g., Demir, 2017; Mali, 2015) can shed light onto learners' attributions for their speaking skills in English as a foreign language, but there is still a need to look into learners' attributions for their speaking skills to understand their motivational states, especially of those who enrolled in ELT departments and would like to become teachers of English in the future. To the best knowledge of the authors, there does not exist a study which has investigated learners' attributions for 
their speaking skills in this particular context. This study, therefore, aims to identify the attributions of ELT students' attributions for their successes or failures in oral communication skills course. To achieve this aim, the study sought to find answers to the following research questions:

1. To what do ELT students attribute their performances in oral presentations?

2. How do these attributions change in accordance with the perceived success in oral presentations of the ELT students?

\section{Method}

Unlike the main trend in studies concerning attributions, the study followed a recent path and it employed a qualitative research design in order to describe the role of EFL learners' attributions for their oral communication performances in EFL classrooms (Mercer et al., 2012). As suggested by Dörnyei and Ryan (2015), qualitative methods enable attribution researchers to constitute a more fruitful methodological foundation. Therefore by adopting the grounded theory approach (Strauss \& Corbin, 1990), the study aims to define and illustrate the place of attributions in shaping EFL learners' achievement in oral communication (Creswell, 2014).

\subsection{Settings and participants}

This qualitative study was conducted at a state university in Turkey after obtaining the consent of participation from the English major students being invited for the study. The participants of the study were learners of the English language enrolled in a four-year-long ELT program. They were all taking the compulsory course "oral expression skills" in the second year of the ELT curriculum. The participants took the course in order to improve their oral communication and expression skills in a way that aimed to help them learn effective communication and presentation skills in English.

At the time of data collection, there were 99 students taking the course in three different sections. Of 99 students, 91 students enrolled in the course participated in the study. The preliminary analyses of the data indicated that eight participants neglected to share their attributions for their final performance in the course. Therefore, they were excluded from the analysis and the data analysis was performed on a data set including 83 participants. There is a female dominance in the participants: over half the participants $(n=53 ; 64 \%)$ were female and $36 \%(n=30)$ were male. In order to begin their education in the program, they had to meet the language proficiency prerequisite to at least upper intermediate level based on the results of the proficiency exam covering four skills and administered by the Foreign Language School at the same university. Therefore, it could be inferred that all of the participants had -at the very least- an upper intermediate level in each skill. 
In line with the aim of the study to investigate the role of achievement in learners' attributions for their communication skills, the participants were divided into two groups based on their self-assessments of the final performance of a ten-minute presentation as a public speaker, including an introduction, a body and a conclusion section. They were asked to assess their own performances by use of a scale ranging from (1) unsuccessful to (10) successful. The data suggested that no students assessed themselves in the rank of 1-3 and 3 was the minimum score that they gave to themselves. Then, the learners giving their performances scores of between 3-6 were grouped as the less-successful learners in expressing their ideas orally to a group of listeners, while the ones assessing themselves by selecting score of 7-10 were identified as more successful learners. Of 83 learners, $24 \%(n=20)$ were in the less successful group while the majority of them $(n=63 ; 76 \%)$ were found to be in the more successful group. To fully recognize the methods employed in the study, the procedures followed throughout the course in which the study was conducted will be presented in the following subsection.

\subsection{Procedure: The course}

Data were collected from the English language learners taking the 'oral communication skills' course. After taking two oral communication related courses in the first year of education in the program, all second-year students of the ELT program had to enrol in the course in order to develop their communication skills, enrich their audio-visual delivery of the content and help them face and overcome their anxiety through oral and written feedback. Given the number of students in the program, the course was offered in three different sections. The students in each section had three-hour classes once a week for a semester of 14 weeks. The classes were instructed by a consortium of staff including a full-time professor and four research assistants, who were all $\mathrm{PhD}$ candidates in the field of ELT at the time of data collection. The first five weeks included the lectures given by the full-time professor on the effective techniques and strategies to become a qualified speaker while the remaining nine weeks were booked for students' performances on a pre- and self-selected topic. During the lecture weeks, the students were informed that they were to make two presentations on a topic. Rather than assigning a topic or a field of presentation, the students had independence to choose their topic based on their interests and likes, in order to reduce the negative effect of speaking on an undesired topic. To exemplify, students chose to talk about their favourite movies, books, places or even contemporary topics such as travel to space and so on.

Of nine allocated weeks for presentations, the first three weeks were given for the students to perform the introduction part of their speech in three minutes. This part includes introducing themselves, their rules, the outline of their speech and their topics. In the last six weeks of the classes, each student enrolled in the course had a chance to give a speech on their topic for ten minutes. This speech was called the main presentation and it included an introduction, which could be the same as the first presentation, a body and a conclusion. 
The target listeners of these two speeches were their peers and at least two lecturers. After each presentation, they had oral feedback from the lecturers and voluntary peers as well as written feedback. Every speaker of the day had to print fifteen copies of a written feedback form and distribute them randomly to their peers. This form comprised sections related to attention to physical appearance and presentability, preparation, materials, delivery, coverage, and conclusion. While the lecturers wrote their names on the form, the peers had no obligations to reveal their names. The speakers of the day collected these written forms to place in their portfolios. In addition to the feedback that the students got in the classroom, they had the chance to arrange a time-slot with one of the lecturers in order to clarify the comments about their performances.

The students additionally ensured that their presentations were recorded. They asked one of their peers to record their performances through their own mobile phones. Furthermore, they provided either a video recorder or their mobile phones to video-tape their two performances so that the risk of technical problems in recordings would be decreased. After watching their performances, the students were to write a self-assessment report for each of their presentations. These reports were also filed in their portfolios as well.

The overall assessment of the course was based on portfolio assessment. The students needed to provide a soft copy of their materials used during the presentations, the video-recordings of their presentations, the scanned format of the written feedback forms filled in by the lecturers and their peers as well as their selfassessment reports for both introduction speech and the main speech. In a meeting of the five lecturers of the course, the performances and the content of the portfolios of each presenter were discussed and a score was given at the end of these discussions. However, rather than the use of this score as an indicator of achievement in oral communication skills, the present study chose to use the self-assessments of the speakers for their main speech.

In the current study, considering that the first speech was the introduction to the main speech and the participants mostly made the same introduction in the main one, the students were asked to assess their performances only in the main speech and provide the attributions to these assessments. They were divided into two groups by the researchers, who were the members of the lecture consortium, as less successful and more successful based on their self-assessment scores ranging between 1-10. Details about the data collection and analysis procedure in this course will be provided in the following sub-section.

\subsection{Data collection and analysis}

Data were collected through an online survey tool, Google Forms, at the end of the semester. The participants of the study were asked to assess their final performance in the classroom and share the reason for their assessment in an open-ended questionnaire format. The researchers sent the link of the survey through an e-mail to 
all of the students enrolled in the course after obtaining their consent for participation. Of 99 students, 91 of them filled in the form. Thus, the return rate (90\%) was quite satisfactory. Access to the survey was purposefully limited to the period before the announcement of the final results, so as not to have the impact of their grades on the study. Therefore, it took approximately three weeks to collect the data.

After the collection of data, the data set was transferred into an Excel sheet. Firstly, the students were grouped as less successful and more successful based on their rankings. In order to present an illustration of attributions for speaking performances, a qualitative content analysis method was employed in the present study. The reasons given in the self-assessment for their performances were read several times by two of the researchers. They coded the data set individually and then, they compared their codes. Following this, they categorized their codes in line with Weiner's attribution theory (2010). These categories helped them to reach three dimensions of attributions as themes. The inter-coder reliability of this analysis was found to be .87 calculated through the formula by Young (1996) and employed by Erten (1998) and Aksoy (2018) to reflect the correlation between the codes of the researchers. The formula involved dividing the number of attributions coded same by the two researchers to the number of units coded by the researchers. For the conflicting answers, the researchers shared their opinions and as a result, a consensus was mostly achieved. Each student was given an ID number to ensure anonymity and the most unexpected excerpts were presented along with these ID numbers in the results section.

\section{Results}

\subsection{Attributions for the speaking performances}

This study initially sought to explore the attributions that the participants of the study stated for their ten-minute speeches referred to as presentations throughout the study. These presentations were naturally a public speaking activity, in which the speakers addressed a group of listeners to present their preplanned speech. Therefore, the participants firstly assessed their own public speaking performances as successful or poor and then, they provided reasons for their successes or failures. The qualitative content analysis employed for these reasons, of which details are presented in Table 1, indicated that the participants agreed on 10 attributions to explain their selfassessment of performances as a public speaker though they had no previous guidance with regards to these reasons. 
Table 1. Attributions for the speaking performances

\begin{tabular}{lll}
\hline Themes & Codes & $\mathrm{f}^{*}$ \\
\hline Internal/Controllable/Unstable & strategy use & 39 \\
Internal/Controllable/Unstable & effort & 37 \\
Internal/Controllable/Unstable & topic choice & 10 \\
Internal/Uncontrollable/Unstable & mood & 28 \\
Internal/Uncontrollable/Unstable & interest & 3 \\
Internal/Uncontrollable/Stable & personality & 5 \\
Internal/Uncontrollable/Stable & linguistic deficiency & 2 \\
External/Controllable/Unstable & acquaintance (expertise from experience) & 17 \\
External/Uncontrollable/Unstable & technical problems & 5 \\
External/Uncontrollable/Unstable & classroom environment & 4
\end{tabular}

*Some participants may have reported more than one attribution for their performances in the open-ended questionnaire. Therefore, the total frequencies of the codes are not necessarily equal to total frequencies of the participants.

The ELT program students participating in the study attributed their performances mostly to the internal, controllable and unstable dimensions based on Weiner's categorization (2010) as presented in Table 1. Of 83 participants, 37 stated that the effort that they made to get prepared for their speeches was the reason for either their successes or failures in their presentations. The participant called a ID23 indicated that she found her presentation successful because she studied harder for long hours and rehearsed it for a couple of times. On the other hand, Participant ID89 assessed himself less successful by scoring his performance 3 and reported that he found himself less successful due to the need for boosting his self-confidence and doing more practice by studying harder. In this sense, he attributed his failure to both personality and lack of effort.

In addition to effort, strategy use was the other appealing reason for the participants to explain their performances. In the lectures, the participants were provided with detailed information about some strategies to become effective speakers such as getting feedback from the listeners, effective use of voice, enhancing body language, preparing speaker notes, timing, signposting, recording and watching their previous speech as well as rehearsing the speech. Almost half of the participants $(\mathrm{n}=39,47 \%)$ indicated that either the effective or ineffective use of strategies were the reasons for their achievement in the presentations. For instance, Participant ID4 indicated that he found himself successful because he considered the feedback given for his first speech while getting prepared and he organized his speech in line with the strategies such as use of visual aids, rehearsals, and voice control. By highlighting the impact of strategy use on her presentation, Participant ID55 mentioned that even if she found herself successful by giving her performance 7 out of 10, she lacked some strategies such as use of speaker notes and keeping eye contact with the listeners. For her, these points affected her performance negatively so that she could not give a higher score to her performance.

The last factor underlying the participants' performances in the Weiner's internal, controllable and unstable (2010) dimension was their topic selection. As shown in 
Table 1, ten participants (12\%) agreed that their choice of topic affected their performance either positively or negatively. While the answer of Participant ID9 reflected the positive effect of selecting an appropriate topic to talk about, Participant ID44 indicated the negative effect of her topic choice. Participant ID9 assessed herself as successful in her performance and she was quite sure about the impact of her topic choice on this assessment by saying:

"My choice of an attractive and entertaining topic contributed to my performance a lot, of course. And I did my best to make my presentation informative and fun..." (ID9, female, more successful [translated from Turkish]).

Echoing the effect of topic selection on the speeches, as stated by Participant ID9, the participant called ID44 found herself less successful due to the topic. She clearly stated that she felt sorry for her performance since she assumed that she was quite successful at her voice control and timing. However, she thought that she chose a very broad topic for a ten-minute speech. She found her topic selection responsible for her poor performance by saying "the problem in my presentation was my topic selection" (ID44, female, less successful [translated from Turkish]).

As shown in Table 1, in the internal, uncontrollable and unstable dimension based on Weiner's categorization (2010), mood of the participants at the time of the speech had an either positive or negative impact according to the views of 28 participants (34\%). For the students who considered that they had a poor performance, the feelings of tension and anxiety during the presentations had a negative effect on their performances, unlike the ones who found themselves successful. For instance, Participant ID28 declared that she could not manage to give an effective speech even if she practiced a lot beforehand because she was nervous during the speech. However, the participants who considered that they were successful attributed their performance to mood because they were not nervous or anxious during their presentations. As a representative, the response of Participant ID33 could be regarded. She gave her performance 9 out of 10 and she directly stated that she was quite successful since she did not get anxious during her speech.

In addition to mood, interest in giving a speech was another factor influencing the participants' performance according to the reflections of three participants (4\%). Interest as a code was also another factor in the category of internal, uncontrollable and unstable dimension based on Weiner's classification (2010). Participant ID26 assessed his performance as poor and to the question about the reason for his assessment, he directly wrote a lack of interest in giving speeches. Participant ID75 who considered her performance differently, stated that she had a special interest in both the topic and addressing others as a speaker. For her, this interest was the reason of her success in her presentation.

Of 83 participants, two (\%2) stated that their linguistic deficiency was the reason for their failure in the presentation while five participants (6\%) mentioned their personality as the reason for their achievement in the presentations. These two codes belonged to the internal, uncontrollable and stable dimension in Weiner's 
classifications (2010). In addition to these two participants who thought that they gave poor performances due to their insufficient speaking skills, in the same dimension there are five participants who considered the reasons was their personality. Of five participants who attributed success and failure in the presentations to their personality, three indicated that being timid or diffident was the reason for their self-assessment as having a poor performance. The two participants stated that as a personal characteristic, they were confident of being successful in speeches. Participant with the ID number 5, for example, stated the reason for the poor performance as:

"I am just shy and timid." (ID5, male, less successful [translated from Turkish]).

Apart from the internal reasons for the achievement in the presentations, the participants of the study also declared external reasons. The most appealing group of external reasons belonged to the external, controllable and unstable category in Weiner's classification (2010). Seventeen participants in total stated that acquaintance referred to as having perceived expertise based on experience and familiarity with the task, was the reason for their self-assessment as successful or poor. As Participant ID87, whose reflections are presented in the following, 16 further participants mentioned that they were successful in the presentations since they gained experience in the previous presentation in which they introduced their speech in three minutes. Participant ID87 clarified the positive influence of getting feedback on improving public speaking skills by stating:

"The feedback I received in the first presentation contributed greatly to my improvement in my main presentation and I was able to find all the answers to the question of how to make a good presentation in the theoretical information during the lectures so that I improved my good features by enriching my main presentation (ID87, female, more successful [translated from Turkish]).

Participant ID81, on the other hand, was the only student who considered acquaintance as a reason for his poor performance. He also emphasized the influence of experience on giving an effective speech. However, he perceived himself as inexperienced in addressing a group of people. Therefore, for his self-assessment of his performance as poor, he denoted a lack of experience as a reason.

The analysis of this study also revealed that the participants attributed external, unstable as well as uncontrollable reasons to explain their success or failure in giving speeches. Five students stated that they overcame some problems in their presentations due to unpredicted technical difficulties such as losing speaker notes, not being able to use the pointer appropriately or forgetting to bring the supplementary documents to the classroom. The participant with ID number 29 scored her performance by giving 8 , which could be inferred that she found herself successful in her performance. However, she mentioned that she would have deserved a full score if she had not forgotten to print the feedback forms. She reflected her opinions as follows: 
“... I could not exactly explain this by saying I was not prepared, because it was not true. My main presentation was probably the task I prepared for most throughout all my school life. I worked very hard and rehearsed my speech a lot. I was at the faculty one hour before the presentation, and I wanted to rehearse it again in the classroom to become sure of everything. While I barely noticed my excitement, I realized that my feedback forms were not the right forms; then everything turned upside down. While trying to go to the stationery shop, the lecturers went to the classroom, the photocopier was closed etc. Such problems unfortunately destroyed all my motivation so that I was not able to show my exact potential (ID29, female, more successful [translated from Turkish]).

The last reason applicable to the external, uncontrollable and unstable dimension that the participants of this study suggested for their performances was related to the contextual factor, namely, the classroom environment. While three participants (4\%) attributed their success in the presentation to the classroom environment, mostly to their peers, by referring to the support that they received from them, as indicated by Participant ID61, only one student (ID14) stated that the positive environment the lecturers created in the classroom contributed to their success in their presentation.

\subsection{The effect of perceived success on attributions}

This study additionally aimed to explore the difference observed in the attributions of the participants who perceived their performances as successful or poor. The number of participants in each group was not equal. However, this is not a barrier to illustrate a picture of any differences between their attributions.

Table 2. The effect of perceived success on attributions

\begin{tabular}{|c|c|c|c|}
\hline Themes & Codes & $\begin{array}{c}\text { More Successful } \\
\qquad(\mathrm{n}=63) \\
\mathrm{f}^{*}\end{array}$ & $\begin{array}{c}\text { Less Successful } \\
\qquad \begin{array}{c}(\mathrm{n}=20) \\
\mathrm{f}^{*}\end{array}\end{array}$ \\
\hline Internal/Controllable/Unstable & strategy use & 35 & 4 \\
\hline Internal/Controllable/Unstable & effort & 30 & 7 \\
\hline Internal/Controllable/Unstable & topic choice & 7 & 3 \\
\hline Internal/Uncontrollable/Unstable & $\operatorname{mood}$ & 21 & 7 \\
\hline Internal/Uncontrollable/Unstable & interest & 2 & 1 \\
\hline Internal/Uncontrollable/Stable & personality & 2 & 3 \\
\hline Internal/Uncontrollable/Stable & linguistic deficiency & - & 2 \\
\hline External/Controllable/Unstable & acquaintance & 16 & 1 \\
\hline External/Uncontrollable/Unstable & classroom environment & 4 & - \\
\hline External/Uncontrollable/Unstable & technical problems & 2 & 3 \\
\hline
\end{tabular}

*Some participants may have reported more than one attribution for their performances in the open-ended questionnaire. Therefore, the total frequencies of the codes are not necessarily equal to total frequencies of the participants.

As presented in Table 2, the participants $(n=20)$ who found their speaking performance less successful or poor attributed it mostly to internal factors. Only a minority of students ( $\mathrm{n}=4$ in total) in this group stated that the reasons for their 
performance was tied to external reasons, which were a lack of experience and the appearance of technical problems. In addition, this group of students mostly indicated that their mood and lack of effort, being equal in number $(n=7)$, were the reasons for their deficient performance in the ten-minute presentation. It was interesting to observe that none of the students suggested the classroom environment influenced on their speeches.

Table 2 also shows that the majority of the participants $(n=63)$ was in the group of more successful students, based on their self-assessments. Echoing their peers in the less successful group, they attributed their self-assessments to internal reasons mostly. While the influence of effort $(n=30)$ and $\operatorname{mood}(n=21)$ was stated by a majority of students in this group, just over half of them $(n=35)$ indicated the impact of strategy use on their perceived success in the presentations. Of the external reasons, the effect of acquaintance was mentioned more than the other two reasons in this category.

\section{Discussion}

It is firstly noteworthy to find that similar attributions are stated by the students in the particular context even though there was not a guiding statement or question for revealing participants' attributions. This also might have led them to see their perceived performances attributed to more than a single reason by some of the students. Similarly, some of the students stated both positive and negative reasons for their performances as well. Consequently, the qualitative data collected for the study can provide a deep insight into the learners' attributions, specifically for their public speaking performances.

Overall, the analysis of the qualitative data shows that learners attributed their perceived successes or failures in their presentations mostly to the use of effective strategy/lack of strategy, personality, mood, effort/lack of effort, facing technical problems, ability, topic choice, interest/lack of interest, classroom environment, teacher, peers and finally, acquaintance with the given task. Some of the findings are similar to what Demir (2017) found in his study as well. For instance, he concluded that learners tended to attribute their successes to practice/exposure, determination/interest, and their failures to lack of study/practice, ineffectiveness of learning environment and lack of self-confidence/anxiety. In his study with Indonesian learners, Mali (2015) found that learners attributed their achievements in speaking to the clear purpose of doing particular English speaking activities, strategy, and the positive motivation/encouragement from friends as well as from the teacher, which yielded different results between his research and the current study. The reason for finding both alike and unalike attributions might be due to the difference in the learning activity, i.e. presentations in the current context, which may have led to participants finding different attributions for their speaking abilities (Williams, Burden, Poulet, \& Maun, 2004). In Demir's (2017) study, the learners were asked to provide their self-perceived success in speaking English as well as the most important 
single cause for success or failure in speaking English. Mali (2015) decided on three specific indicators that he regarded as the most frequently performed activities by the students during the class. These indicators were given as "students' ability [1] in doing a monologue using English actively in front of the classroom; [2] in asking their friends questions using English actively; and [3] in answering the questions proposed by their friends using English actively" (p. 34). It is obvious that these two studies focused on learners' speaking abilities in mutual conversation settings. The given task in the current context was to have students make a presentation on a topic that they chose themselves. According to Lightfoot (n.d.), this kind of task is defined as "public speaking that involves talking in front of a group of people, usually with some preparation". In public speaking tasks, learners do not have to engage in a mutual conversation with other people. Therefore, the inherent characteristics of the activities used in the three studies might have caused different attributions to be found.

When each individual attribution is considered, apart from 'facing technical problems', 'acquaintance with the given task', and 'classroom environment', the remaining attributions were confirmed as internal attributions by the first two authors of the study. For the learners who declared their dissatisfaction with their final performances, this result offers a satisfactory conclusion because it shows that the learners can have control over the reasons that they are supposed to have affected their performances. It is possible to further group these internal attributions in accordance with stability and controllability dimensions (Weiner, 1992, 2010). At this point, 'personality' and 'ability' can be perceived as undesired attributions because they are regarded as uncontrollable and stable internal attributions. Attributing one's failure to those reasons can cause the person to develop a sense of 'learned helplessness' and the individual will not execute any effort to change his/her behavior in future trials. In terms of the current context, students who regarded their performances as less successful due to their personality or ability might also develop a sense of speaking anxiety and refrain from taking turns in the classroom or they might not want to be called upon to speak by the teacher. Similarly, participants who regarded their performances as successful due to their personality or ability might not put effort into future tasks. It is satisfactory, though, to see that the students with less successful performances have attributed their performances to their lack of either effort or use of effective strategies or more successful students to the effective use of strategies or effort.

Students also attributed their performances to external reasons such as 'facing technical problems', 'acquaintance with the given task', 'classroom environment', 'teacher' and 'peers'. Attribution theory (Weiner, 1976) suggests that external, unchangeable and uncontrollable attributions will be likely to cause a less consistent effect than internal attributions. In this regard, the students who attributed their performances solely to these reasons may be unwilling to put effort into the given tasks in the future. 


\subsection{Individual attributions given by the students}

Here the most unexpected results will be discussed in relation to the literature. Firstly, it was observed that the students who regarded their performances as more successful stated 'classroom environment' had a positive impact on their performances. For instance, a student (ID79) stated:

The presentation before this and feedbacks that I got earlier to this provided this successful period. Also, the comments that I listened during my friend's presentation helped me to be successful. I must be thankful for this presentation class. It really helped and it was really productive (ID 79, female, more successful [original words])

This was supported by another student (ID46) who mentioned:

Feedback and my classmates' presentations. (ID 46, male, more successful [translated from Turkish])

This finding was quite the opposite of Demir's (2017) study in which the participants attributed their failures to ineffectiveness of the learning environment. Therefore, it can be concluded that observing peers' presentations created a chance for "vicarious learning" (Lee, Dineen, McKendree, \& Mayes, 1999). Both of these students and some others in the study stated the positive impact of the teacher feedback on their performances provided in the class (Smith, \& King, 2004). Based on this, it can be claimed that immediate teacher feedback would have a positive effect on students' attributions and motivation (Entika, \& Ling, 2019) and in turn on their performances as well (King, Young, \& Behnke, 2000). Providing immediate feedback might have caused the effect of attribution retraining that includes "specific teacher feedback confirming learners' adequate abilities and emphasizing the effort and perseverance required to complete a given task successfully" (Hsieh \& Kang, 2010, p. 622).

Another interesting result was to find one learner's attribution to her peers. She (ID61) spoke about:

The responsibility of being the second-year student, studying and preparing well and also people who are always with me and relax me, of course. (ID61, female, more successful [translated from Turkish])

Mali (2015) also found the positive impact of positive motivation/encouragement from friends as a mediating factor in learners' speaking achievements. As Dörnyei (2007) mentions, creating a motivating classroom environment has utmost importance for learning achievement in the longer-term. Concepts such as group cohesiveness, interpersonal relations and the teacher's leadership styles are some of the key concepts for creating a motivating classroom environment. Vicarious experiences (Mills, 2009) such as presentations or in-class discussions in a foreign language curriculum can affect learners' self-efficacy beliefs by allowing them to observe their peers at similar proficiency levels. Mills (2009) suggests that this will create a shared sense of collective efficacy. 
The teacher's influence on the students' attributions is almost unobservable in the current research. Several studies concluded that learners tended to attribute their successes to external factors such as their teacher (Erten \& Burden, 2014; Peacock, 2009; Tse, 2000). For instance, in a Turkish context, Erten and Burden (2014) refers to the highly respected status of teaching and teachers for the explanation of this finding. However, the current research failed to find any impact of teachers on learners' attributions.

Another reason attributed to their performances by the students is acquaintance with the given task. The learners also attributed their successes in speaking to 'practice' and their failures to the 'lack of practice' conversely. Although both of the attributions do not seem to be equal to each other, gaining expertise in a task seems to have a contributing factor to learners' achievement. This was supported by the following statement of one of the students (ID71):

After the first presentation, I realized my mistakes and I tried to fix them and I rehearsed more. Having done so, I realized that I made an improvement when I compare it to my first presentation. (ID71, female, more successful, [translated from Turkish])

Another student (ID57) also mentioned:

Rehearsing a lot and acquiring familiarity, because we have been doing presentations since last year. (ID57, male, more successful [translated from Turkish])

Many of the participants who regarded their performances as more successful attributed their successes to this factor. Therefore, having students rehearse the tasks, i.e. presentations in the current context, can increase their self-efficacy and also achievement.

\section{Conclusions}

As has been suggested previously, causal attributions can predict and improve academic performance. In order to increase students' achievement and motivation, teachers need to understand their learners' attributions for their successes and failures in specific tasks such as public presentations, as in this case, a context which has not been explored by the researchers before.

It is promising to find out that learners who have either higher or lower selfperceived success attribute their performances to more internal, controllable and changeable reasons. Although many learners mention some external factors such as 'classroom environment', 'acquaintance with the task', or 'peers' as contributing to their successes, these also can inform teachers about creating a motivating environment in the classrooms, providing immediate teacher feedback, and applying similar tasks for increasing learners' self-efficacy. These findings can help teachers who teach speaking skills in foreign language contexts and also university lecturers who give speaking skills courses in English Language Teaching programs. 
The results of this small-scale study can shed light on the learners' attributions for their public speaking performances, but it would be better to include more participants in future studies. As for another limitation, it should be noted that the learners may have been biased to give these explanations for their performances because they were asked to provide explanations for their performances by their course convenors. Still, the learners seem to have provided their genuine explanations for their performances.

\section{Acknowledgements}

This research was presented at GlobELT 2017 Conference: An International Conference on Teaching and Learning English as an Additional Language, 18-21 May 2017, Ephesus, İzmir, Turkey by the first and third author of the study. We would like to thank Prof. Dr. İsmail Hakkı ERTEN, who has touched our lives in academia as novice researchers and teachers by his endless support and encouragement. It has been and will always be a great honour for us to be his $\mathrm{PhD}$ students, colleagues and even spiritual daughters. This piece is the first study that we are able to publish collaboratively with him and we do hope that this will cheer him up where he is now. He will be always dearly missed and may his soul always rest in peace. We also would like to thank the all participants and the reviewers of the study.

\section{The Research and Publication Ethics Statement}

Data were collected after getting the consent of the participants. No ethical considerations were violated in this study.

\section{The Conflict of Interest Statement}

In line with the statement of Committee on Publication Ethics (COPE), we hereby declare that we had no conflicting interests regarding any parties of this study.

\section{References}

Aksoy, K. (2018). An investigation into collaborative behaviours in task-based foreign language peer interactions (Unpublished doctoral dissertation). Hacettepe University, Ankara, Turkey.

Alagözlü, N. (2012). English as a foreign language cul-de-sac in Turkey. Procedia - Social and Behavioral Sciences, 47, 1757-1761.

Bayraktar-Erten, N., \& Erten, I. H. (2014). Academic self-concept and students' achievement in the sixth grade Turkish course: A preliminary analysis. International Online Journal of Education and Teaching, 1(2), 46-55.

British Council \& TEPAV (2014). Türkiye'deki Devlet Okullarında İngilizce Dilinin Öğretimine İlişkin Ulusal İhtiyaç Analizi (Turkey National Needs Assessment of State Schools English Language Teaching) [PDF file]. Retrieved from https://tinyurl.com/t5psgh6

British Council \& TEPAV (2015). Türkiye'de yükseköğretim kurumlarındaki İngilizce eğitimi [PDF file]. Retrieved from https://tinyurl.com/y4f63m9t

Creswell, (2014). Research design: Qualitative, quantitative, and mixed methods approaches. Thousand Oaks, California: Sage Publications. 
Demir, Y. (2017). Turkish EFL learners' attributions for success and failure in speaking English. International Journal of Contemporary Educational Research, 4(2), 39-47.

Dörnyei, Z. (2005). The psychology of the language learner: Individual differences in second language acquisition. USA: Lawrence Erlbaum Associates.

Dörnyei, Z. (2007). Creating a motivating classroom environment. In J. Cummins, C. Davison (Eds.), International Handbook of English Language Teaching (pp 719-731). Boston: Springer.

Dörnyei, Z., \& Ryan, S. (2015). The psychology of the language learner revisited. New York, NY: Routledge.

EF English Proficiency Index (EPI) (2019). A Ranking of 100 Countries and Regions by English Skills. Retrieved from https://tinyurl.com/uoea8yv .

Entika, H.S.A., \& Ling, Y. (2019). The importance of immediate constructive feedback on students' instrumental motivation in speaking in English. Britain International of Linguistics, Arts and Education (BIoLAE) Journal, 1(2), 1-7. doi:https://doi.org/10.33258/biolae.v1i2.58

Erten, İ. H. (1998). Vocabulary learning strategies: An investigation into the effect of perceptual learning styles and modality of word presentation on the use of vocabulary learning strategies (Unpublished doctoral dissertation). University of Exeter, United Kingdom.

Erten, İ. H. (2009). Gender differences in academic achievement among Turkish prospective teachers of English as a foreign language. European Journal of Teacher Education, 32(1), 75-91.

Erten, İ. H. (2015). Age related gender differences in causal attributions of Turkish learners of English as a foreign language. ELT Research Journal, 4(2), 129-146.

Erten, İ. H., \& Burden, R. (2014). The relationship between academic self-concept, attributions, and L2 achievement. System, 42, 391-401.

Faber, G. (2019). Longitudinal effects of task performance and self-concept on preadolescent EFL learners' causal attributions of grammar success and failure. Studies in Second Language Learning and Teaching, 9(4), 633-656. doi: 10.14746/ssllt.2019.9.4.4

Genç, G. (2016). Attributions to success and failure in English Language learning: The effects of gender, age and perceived success. European Journal of Education Studies, 2(12), 25-42.

Gürsoy, E., \& Çelik-Korkmaz, Ş. (2015). Teacher trainers as action researchers: Scrutinizing the reasons for student failure. Journal of Language and Linguistic Studies, 11(2), 83-98.

Hashemi, M. R., \& Zabihi, R. (2011). Learners' attributional beliefs in success or failure and their performance on the interchange objective placement test. Theory and Practice in Language Studies, 1(8), 954-960.

Hsieh, P. (2012). Attribution: Looking back and ahead at the 'why' theory. In S. Mercer, S. Ryan \& M. Williams (Eds.), Psychology for language learning: Insights from research, theory and Practice (pp.90-102). Hampshire, UK: Palgrave Macmillan.

Hsieh, P. H., \& Kang, H. (2010). Attribution and self-efficacy and their interrelationship in the Korean EFL context. Language Learning, 60(3), 606-627.

Hsieh, P. H., \& Schallert, D. L. (2008). Implications from self-efficacy and attribution theories for an understanding of undergraduates' motivation in a foreign language course. Contemporary Educational Psychology, 33, 513-532.

Işık, A. (2011). Language education and ELT materials in Turkey from the path dependence perspective. Hacettepe University Journal of Education, 40, 256-266.

King, P. E., Young, M. J., \& Behnke, R. R. (2000). Public speaking performance improvement as a function of information processing in immediate and delayed feedback interventions. Communication Education, 49(4), 365-374. doi: 10.1080/03634520009379224 
Koçyiğit, M. (2011). Causal attributions and learning styles of university students. Unpublished MA thesis. Afyon Kocatepe University, Afyonkarahisar.

Larsen-Freeman, D. (2000). Techniques and principles in language teaching (2 ${ }^{\text {nd }}$ ed.). Oxford: Oxford University Press.

Lee, J., Dineen, F., McKendree, J., \& Mayes, T. (1999). Vicarious learning: Cognitive and linguistic effects of observing peer discussions. Paper presented at American Educational Research Association, AERA '99, Montreal, Quebec, 20-23 April, 1999.

Lian, X. (2012). An empirical study on causal attribution regarding listening achievement of Chinese English majors. Contemporary English Teaching and Learning in Non-EnglishSpeaking Countries, 1(1), 23-46.

Lightfoot, A. (n.d.) Public speaking skills. Retrieved from https://tinyurl.com/y5bueup5 .

Mali, Y. C. G. (2015). Students' attributions on their English speaking enhancement. Indonesian Journal of Applied Linguistics, 4(2), 32-43.

McAuley, E., Duncan, T., \& Russell, D. (1992). Measuring causal attributions: The revised Causal Dimension Scale (CDSII). Personality and Social Psychology Bulletin, 18, 566-573.

Mercer, S., Ryan, S., \& Williams, M. (2012). Psychology for language learning: Insights from research, theory and Practice. Hampshire, UK: Palgrave Macmillan.

Mills, N.A. (2009) A 'Guide du Routard' simulation: Enhancing the standards through projectbased learning. Foreign Language Annals, 42(4), 607-639.

Paker, T., \& Özkardeş-Döğüş, A. (2017). Achievement attributions of preparatory class learners in learning English. Journal of Language and Linguistic Studies, 13(2), 109-135.

Peacock, M. (2009). Attribution and learning English as a foreign language. ELT Journal, 64(2), 184-193.

Petek, (2014). The teacher as a public speaker in the classroom. Studies in Literature and Language, 9(1), 124-133.

Pishghadam, R., \& Modarresi, G. (2008). The construct validation and application of a questionnaire of attribution theory for foreign language learners (ATFLL). Iranian Journal of Language Studies, 2, 299-324.

Pishghadam, R., \& Zabihi, R. (2011). Foreign Language Attributions and Achievement in Foreign Language Classes. International Journal of Linguistics, 3(1), 1-11.

Satıcılar, U. (2006). An investigation into the achievement attributions of different grade English language learners. Unpublished MA Thesis, Institute of Social Sciences, Çanakkale Onsekiz Mart University, Çanakkale-Turkey.

Smith, C. D., \& King, P. E. (2004). Student feedback sensitivity and the efficacy of feedback interventions in public speaking performance improvement. Communication Education, 53(3), 203-216. doi: 10.1080/0363452042000265152

Strauss, A., \& Corbin, J. (1998). Basics of qualitative research techniques and procedures for developing grounded theory ( $2^{\text {nd }}$ Ed.). London: Sage Publications.

Talim Terbiye Kurulu, (2006). English Language Curriculum for Primary Education. Ankara, MEB.

Tse, L. (2000). Student perceptions of foreign language study: A qualitative analysis of foreign language autobiographies. Modern Language Journal, 84(1), 69-84.

Uztosun, M. S. (2013a). An interpretive study into elementary school English teachers' beliefs and practices in Turkey. Turkish Online Journal of Qualitative Inquiry, 4(1), 20-33.

Uztosun, M. S. (2013b). The role of student negotiation in improving the speaking ability of Turkish university EFL students: An action research study (Unpublished $\mathrm{PhD}$ dissertation). University of Exeter, Exeter: United Kingdom. 
Weiner, B. (1976). Attribution theory, achievement motivation, and the educational process. Review of Educational Research, 42, 203-215.

Weiner, B. (1992). Human motivation: Metaphors, theories and research. Newbury Park, CA: Sage.

Weiner, B. (2000). Interpersonal and intrapersonal theories of motivation from an attributional perspective. Educational Psychology Review, 12, 1-14.

Weiner, B. (2010). The development of an attribution-based theory motivation: A history of ideas. Educational Psychologist, 45(1), 28-36.

Williams, M., \& Burden, R. (1997). Psychology for language teachers. Cambridge: Cambridge University Press.

Williams, M., Burden, R., Poulet, G., \& Maun, I. (2004). Learners' perceptions of their successes and failures in foreign language learning. Language Learning Journal, 30(1), 1929. doi: 10.1080/09571730485200191.

Yılmaz, C. (2012). An investigation into Turkish EFL students' attributions in reading comprehension. Journal of Language Teaching and Research, 3(5), 823-828.

Young, M. C. (1996). Listening comprehension strategies used by university level Chinese students learning English as a second language (Unpublished doctoral dissertation). University of Essex, UK.

Zabihi, R., \& Pordel, M. (2011). Design, application, and factor structure of a cultural capital questionnaire: Predicting foreign language attributions and achievement. English Language and Literature Studies, 1(1), 67-76.

\section{Copyrights}

Copyright for this article is retained by the author(s), with first publication rights granted to the Journal.

This is an open-access article distributed under the terms and conditions of the Creative Commons Attribution license (CC BY-NC-ND) (http://creativecommons.org/licenses/by-nc-nd/4.0/). 